admission. This proportion could already be greater in some parts of the country and may increase if referrals of cases of self-poisoning increase faster than the facilities for their assessment and management. The provision of social work and psychiatric expertise in casualty departments may be one means of preventing unnecessary medical admissions without risk to the patients.

Dr Blake's and Dr Bramble's figures do not demonstrate, however, that any advantage would attach to medical teams taking over assessment from psychiatrists except that, by implication, assessments would be completed sooner by staff working on the ward full time. What the figures actually suggest is that if assessment of overdoses were left to house doctors there would be an increase in admissions to psychiatric units (by $19 \%$ ), outpatients (by $5 \%$ ), and referrals to social services (by $14 \%$ ). So for house doctors to assess overdoses would provide no economy for the psychiatric or social services. The study does not tell us what the consequences would have been for the six patients who the psychiatrists would have admitted but to whom the house doctors would have offered outpatient appointments.

E J SALTER

King's Mill Hospital,

Sutton-in-Ashfield, Notts NG17 4JL

\section{Vitamin D deficiency in Asian immigrants}

SIR,-We agree with your leading article on rickets in the Asian community (30 June, $\mathrm{p}$ 1744) that the diet of Asians should be supplemented with vitamin $\mathrm{D}$, and that attempts to change dietary customs for health reasons are doomed to failure. Nevertheless, we feel that the special need to ensure adequate vitamin $\mathrm{D}$ intake in certain high-risk groups has not been properly emphasised.

The risk of vitamin D deficiency is probably greatest during pregnancy and this risk is not offset by sunlight in the UK. There is certainly more sunlight in London than in Glasgow; nevertheless, in our recently completed double blind trial of vitamin D supplements in pregnancy, $22 \%$ of a placebo group of 60 predominantly middle-class Asian women had plasma $25-\mathrm{OH}$ vitamin $\mathrm{D}$ levels of less than $5 \mathrm{nmol} / \mathrm{l}$ at 28 weeks of pregnancy. At parturition this proportion had increased to $40 \%$, and $45 \%$ of their infants had equally low levels in their cord blood. Such low levels are often associated with osteomalacia and rickets. Five of the infants of the mothers in the placebo group had symptomatic hypocalcaemia in the neonatal period, while none of the 59 infants in the treatment group were affected. After making allowance for the

Comparison of heat-labile alkaline phosphatase concentrations in maternal and umbilical cord plasma of patients receiving vitamin D supplements and those receiving placebo

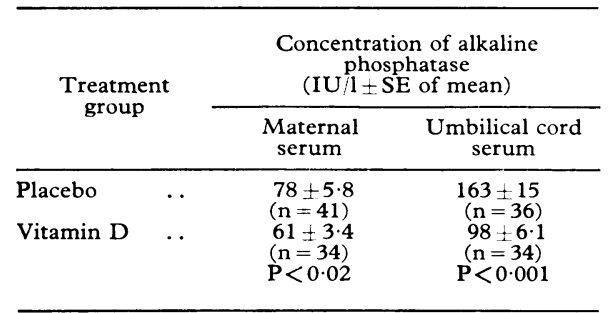

placental isoenzyme, plasma alkaline phosphatase was elevated in the placebo mothers and their infants compared with the treated group (table). Since none of the mothers had raised plasma levels of liver enzymes and since it is known that the bone isoenzyme accounts for more than $80 \%$ of the cord blood activity, these alkaline phosphatase results probably imply subclinical bone disease.

These findings are in preparation for publication but in the meanwhile we would urge all, and in particular obstetricians, who care for pregnant Asian women to ensure that their patients receive adequate vitamin $\mathrm{D}$ supplements.

O G BROOKE

I R F BROWN

H J W Cleeve

St George's Hospital

London SW 17 ORE

SIR,-Two statements in your leading article (30 June, p 1744) might be misleading. The opening sentence states that "rickets virtually disappeared from Britain in 1945 after milk was fortified with vitamin D." It should be made clear that the only milks in Britain fortified with this vitamin are those used for the artificial feeding of infants. At no time has "doorstep" milk been fortified. The second statement which requires clarification is that "rickets and osteomalacia are now found mostly in Asian immigrants to Britain." It is, of course, true that a number of cases of rachitic deformity are found in Asian immigrants, but the problem of vitamin $D$ deficiency is also seen in children of Asian ethnic origin born and reared in the UK. This is of equal or greater concern to health authorities than the occurrence of rickets in those entering the country from Asia or Africa.

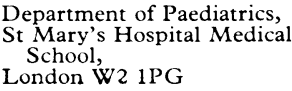

\section{Age and death in breast cancer}

SIR,-Your leading article (27 January, p 211), prompted a preliminary review of some material being collected at Saint Elizabeths Hospital on breast cancer in mental patients. The total number of cases operated on since 1959 is 135, of which 43 records have been reviewed. The total involved population is taken as the estimated female population plus admissions since 1959, a total of 21631 females. The estimated prevalence in this group would be $730 .{ }^{1}$ The true figure is undoubtedly higher since many patients were hospitalised only briefly and lost to follow-up. Patients fell into three diagnostic categories: organic brain syndrome with psychosis (DSM II 290.X294.X), organic brain syndrome without psychosis (DSM II 309.X), and schizophrenia (DSM II 295.X).

Comparison of age of onset of breast cancer and survival suggests that survival decreases with age of onset of breast cancer and calculation of the correlation coefficient confirms this: $\mathrm{r}=-0.4456, t=3.1865, \mathrm{P}<0.005$. This higher death rate, however, is not entirely due to breast cancer but to age per se. Fourteen patients died of breast cancer, 18 from other causes and were clinically free of disease. Age of onset for these groups was $77 \cdot 1 \pm 11$ and $74 \cdot 9 \pm 14 \cdot 6$ respectively, which is not a significant difference and suggests that age of onset does not affect survival either positively or negatively. Various treatments were assigned numerical values which were totalled and averaged for each group. Correlation of survival against treatment gives a disappointing $\mathrm{r}=0.038$. This is misleading because patients with anaplastic or advanced disease receive more chemotherapy and radiation. Older patients, however, tend to be treated more conservatively: for age of onset of breast cancer against treatment: $\mathrm{r}=-0.2774, t=$ $1 \cdot 8494, \mathrm{P}<0 \cdot 1$; not significant, but suggestive. In recent months, considerable interest has been expressed in the possible effect of phenothiazines on the development of breast cancer. ${ }^{2}$ Patients who receive phenothiazines prior to development of breast cancer live longer than those who never received these drugs; but the significance of this is clouded by the marked differences in age. Twenty-five patients who received phenothiazines before developing breast cancer may be compared with 18 who did not receive these drugs. Survival was $3 \cdot 22 \pm 3 \cdot 1$ years for the non-drug group and $4.88 \pm 4 \cdot 3$ years for the phenothiazine group, giving a $t$ of 1.3684 with $P<0.02$. This strongly suggests that, at the worst, phenothiazines do not exert any adverse effects on survival.

Reserpine has also been implicated as a carcinogen. ${ }^{3}$ Comparison of dosage against survival gives an $r$ of $0 \cdot 1445$, which does not support any effect of reserpine on breast cancer: however, there are only nine patients in this group.

The prevalence of breast cancer in schizophrenics appears to be much lower than expected, a phenomenon which has been claimed for cancer in general. ${ }^{4}$

JoHN M GOWDY JAMES D SOLOMON

National Institute of Mental Health,

Washington DC 20032

${ }^{1}$ Seidman, $\mathrm{H}, \mathrm{Ca}-\mathrm{A}$ Cancer fournal for Clinicians,

1978, 27, 66. Smithline, F, and Meltzer, H Y, Archives of General sychiatry, 1978, 3al 1291.
Robinson, B, Medical fournal of Australia, 1957, 2, 239.

- Roppel, R M, Science, 1977, 201, 398.

SIR,-I am surprised that no one has objected to the leading article "Age and death in breast cancer" (27 January, p 211). Anxiety has been aroused in women who had had mastectomy for breast cancer some years before and who, though medically or scientifically untrained, had easy access to the journal. Their distress was caused by their subjective interpretation of an unscientific phrase used in that article-namely, ". . . most women who develop carcinoma of the breast are likely to die of their cancer." Their interpretation was "However long I survive, I am almost certain to suffer death from cancer."

Condemnation of the use of this phrase involves its repetition, with the concomitant risk of causing more distress. (Perhaps this explains the absence of any subsequent reproof from these columns.) Only if its origin is discredited can the unfortunate consequences of its use be mitigated, and the phrase itself consigned to its rightful place in that journalistic limbo between scientific sophistry and aphoristic brevity. The offending phrase is a misquotation from a paper by Mueller et $a l,{ }^{1}$ the paper whose findings and conclusions formed the basis of the leading article, and a paper therefore which your 